\title{
World of Nanobionics
}

ISSN: 2576-8840

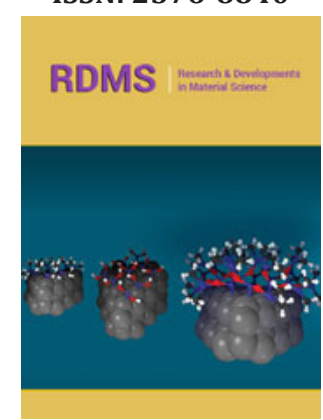

*Corresponding author: Nida Tabassum Khan, Department of Biotechnology, Faculty of Life Sciences and Informatics, Balochistan University of Information Technology Engineering and Management Sciences, (BUITEMS), Quetta, Pakistan

Submission: 酶 November 09, 2020

Published: 址 November 24, 2020

Volume 14 - Issue 3

How to cite this article: Nida Tabassum Khan, Muhammad Jibran Khan. World of Nanobionics. Res Dev Material Sci. 14(3). RDMS.000840. 2020 DOI: $10.31031 /$ RDMS.2020.14.000840

Copyright@ Nida Tabassum Khan. This article is distributed under the terms of the Creative Commons Attribution 4.0 International License, which permits unrestricted use and redistribution provided that the original author and source are credited.

\section{Nida Tabassum Khan ${ }^{1 *}$ and Muhammad Jibran Khan ${ }^{2}$ \\ ${ }^{1}$ Department of Biotechnology, Balochistan University of Information Technology Engineering and Management Sciences,Pakistan}

${ }^{2}$ Department of Electrical Engineering, Balochistan University of Information Technology Engineering and Management Sciences, Pakistan

\section{Abstract}

Nanobionics involves the manipulation of nanomaterials to be employed in several applications in areas like medical, textile, plant biotechnology, microbial technology etc. by enhancing the performance of their existing functions such as higher productivity, variations in molecular adhesion, increased photosynthesis etc.

Keywords: Plants nanobionics; Nanostructures; Nanoceria; Single-walled carbon nanotube; Nanosheets

\section{Introduction}

The term bionics is the study of biological system at nanoscale involving the manipulation of nanomaterial's, to be used in numerous applications [1]. Nanobionics is an alternative approach of nanobiotechnology which alters the properties of materials and these altered properties get translated in various applications during fabrication at nanoscale [2]. Nanobionics offers numerous benefits in various areas by changing properties of materials such as increased surface area, faster reaction rate and switching speeds, higher productivity, variations in protein adhesion/cellular interactions, control of cellular/molecular events etc. [3-7].

\section{Plants nanobionics}

The idea of nanobionics to use in plants was given by Michael [8]. Later nanobionics resulted in countless advancements in the field of plant biotechnology such as improved biochemical sensing and solar energy harnessing in plants by introducing nanomaterial in their cells [9], augmented seed germination, plant growth and development using genetically modified carbon nanotubes etc. [10]. Thus plants nanobionics has an excessive potential to develop novel tools for the integration of nanoparticles into plants to increase the existing functions [11].

\section{Examples}

Increases photosynthesis: With the help of nanobionics technology when non-biological nanostructures are amalgamated with plant organelles such as single walled carbon nanotube when introduced into chloroplast elevates the rate of photosynthesis three times and a higher electron transport was achieved [12,13].

Decreases sensitive oxygen species generation: Single-walled carbon nanotube-nanoceria complex (cerium oxide) when introduced into the chloroplasts, it sequesters the highly reactive molecules to avert the generation of sensitive oxygen species that damages the chloroplast [14,15].

Biochemical sensing and harvesting light in photosynthesis: Scientists all around the globe have continuously tried to develop ways to improve the isolated chloroplast that can be used for solar cells [16]. For example, spinach incorporated with $\mathrm{TiO}_{2}$ speeds up the oxygen evolving rate of photosystem II and electron transport [17]. Similarly, Gold nanoparticles were discovered to upsurge the absorption of photons in the light harvesting molecular complexes thus improves photosynthesis rate by enhancing the rate of electron transport, photophosphorylation as well as augmented oxygen rate [16]. 
Detectors for various chemical present in the environment: Plants bonded with nanoparticles act as chemical detectors to identify their presence in soils, water and air [18].

Glowing plants: Formation of specific nanoparticles into watercress plant leaves resulted in emission of light like a lamp [19].

\section{Medical nanobionics}

Medical nanobionics have numerous applications in the medical field such as in artificial muscles by using electrochemical actuators which stores electric energy and convert it into mechanical energy by using carbon nanotubes, metal oxides, $\mathrm{N}$-doping and nanosheets [20]. In addition, application in nerve stimulation, eye and ear treatment etc. [21,22].

\section{Textile nanobionics}

Using nanobionics in clothing is an efficient method to get rid of diseases caused by free radicals [23]. For example, cloths designed to emit infra-red radiations that decreases the concentration of free radical [24]. Another example is the manufacturing of mineral oxide based polyurethane textile which helps the body to absorb thermal emission and transform it into far infrared radiations [25].

\section{Fungal nanobionics}

Fungal nanobionics offers significant applications for the development of novel medical, industrial, agricultural products [26,27].

\section{Upcoming prospects of nanobionics}

1. Nanobionics has huge potential to produce novel and useful properties for the improvement of solar energy by organisms and also by photosynthetic organelles [28].

2. Nanobionics applications in plants leads to improved grain yield, seed germination etc. [29]

3. Nanomaterials used for the transportation/delivery of DNA/ drugs into the plant cell [30].

\section{Conclusion}

Nanobionics and its applications is a revolutionary science which is enhancing and improving our lives the future we see in science fiction movies, seems to be a reality now with the help of nanobionics.

\section{References}

1. Wallace GG, Higgins MJ, Moulton SE, Wang C (2012) Nanobionics: the impact of nanotechnology on implantable medical bionic devices. Nanoscale 4(15): 4327-4347.

2. Prasad R (2019) Approaches in nanoparticles, biosynthesis, and toxicity Plant Nanobionics, Springer Nature.

3. Enamala MK, Kolapalli B, Sruthi PD, Sarkar S, Kuppam C, Chavali M (2019) Applications of nanomaterials and future prospects for nanobionics. Plant Nanobionics, pp. 177-197.

4. Yadav HK, Alsalloum GA, Al Halabi NA (2018) Nanobionics and nanoengineered prosthetics. Nanostructures for the Engineering of Cells, Tissues and Organs, pp. 513-587.
5. Bueno J (2019) Microbial Nanobionic Engineering: Translational and Transgressive Science of an Antidisciplinary Approximation. Microbial Nanobionics, pp. 177-192.

6. Prasad R (2019) Advances in the understanding of nanomaterials research and applications. Plant Nanobionics, Springer.

7. Luo Q (2020) Printable Electronics Research Center, Suzhou Institute of Nanotech and Nanobionics, Chinese Academy of Sciences, Suzhou, China.

8. Giraldo JP, Landry MP, Faltermeier SM, McNicholas TP, Iverson NM, et al. (2014) Plant nanobionics approach to augment photosynthesis and biochemical sensing. Nature Materials 13(4): 400-408.

9. Lew TTS, Koman VB, Gordiichuk P, Park M, Strano MS (2020) The emergence of plant nanobionics and living plants as technology. Advanced Materials Technologies 5(3): 1900657.

10. Scholes GD, Sargent EH (2014) Bioinspired materials: Boosting plant biology. Nature materials 13(4): 329-331.

11. Khatri K, Rathore MS (2018) Plant nanobionics and its applications for developing plants with improved photosynthetic capacity. Photosynthesis: From Its Evolution to Future Improvements in Photosynthetic Efficiency Using Nanomaterials, pp. 95-112.

12. Li W, Wu S, Zhang H, Zhang X, Zhuang J, et al. (2018) Enhanced biological photosynthetic efficiency using light-harvesting engineering with dualemissive carbon dots. Advanced Functional Materials 28(44): 1804004.

13. Swift TA, Oliver TA, Galan MC, Whitney HM (2019) Functional nanomaterials to augment photosynthesis: evidence and considerations for their responsible use in agricultural applications. Journal of the Royal Society Interface Focus 9(1): 20180048.

14. Wu H, Tito N, Giraldo JP (2017) Anionic cerium oxide nanoparticles protect plant photosynthesis from abiotic stress by scavenging reactive oxygen species. ACS Nano 11(11): 11283-11297.

15. Djanaguiraman M, Nair R, Giraldo JP, Prasad PVV (2018) Cerium oxide nanoparticles decrease drought-induced oxidative damage in sorghum leading to higher photosynthesis and grain yield. ACS Omega 3(10): 14406-14416.

16. Das S, Debnath N, Pradhan S, Goswami A (2017) Enhancement of photon absorption in the light-harvesting complex of isolated chloroplast in the presence of plasmonic gold nanosol-a nanobionic approach towards photosynthesis and plant primary growth augmentation. Gold Bulletin 50(3): 247-257.

17. Rico CM, Peralta-Videa JR, Gardea-Torresdey JL (2015) Chemistry, biochemistry of nanoparticles, and their role in antioxidant defense system in plants. Nanotechnology and Plant Sciences, pp. 1-17.

18. Kwak SY, Wong MH, Lew TTS, Bisker G, Lee MA, et al. (2017) Nanosensor technology applied to living plant systems. Annual Review of Analytical Chemistry 10(1): 113-140.

19. KW SY. Lights made from nature.

20. Khan NT. Nanobionics-nanoscale view of a biological system. Bulletin of the Korean Chemical Society 26(3): 361-370.

21. Shen H, Zhang L, Liu M, Zhang Z (2012) Biomedical applications of graphene. Theranostics 2(3): 283-294.

22. Min LIANG (2013) Application and development of new functional material conducting polymers. Guangzhou Chemical Industry (4): 15.

23. Gonos ES (2016) Ceramic textiles from mineral oxides microfi-bers coating (Nanobionic $囚$ ) efficiently emit infrared rays and reduce free radical levels in healthy volunteers and in patients with free radical-related disorders. J Med Chem Toxicol 1(1): 1-7.

24. Di J, Zhang X, Yong Z, Zhang Y, Li D, Li R, Li Q (2016) Carbon-nanotube fibers for wearable devices and smart textiles. Advanced Materials 28(47): 10529-10538. 
25. Papacharalambous M, Karvounis G, Kenanakis G, Gupta A, Rubinsky B (2019) The effect of textiles impregnated with particles with high emissivity in the far infrared, on the temperature of the cold hand. Journal of Biomechanical Engineering 141(3).

26. Prasad R, Kumar V, Kumar M, Wang S (2018) Fungal nanobionics: principles and applications. Springer, Singapore.

27. Prasad R (2019) Microbial nanobionics. Springer International Publishing.
28. Sekar N, Ramasamy RP (2015) Recent advances in photosynthetic energy conversion. Journal of Photochemistry and Photobiology C: Photochemistry Reviews 22: 19-33.

29. Hatami M, Kariman K, Ghorbanpour M (2016) Engineered nanomaterialmediated changes in the metabolism of terrestrial plants. Science of the Total Environment 571: 275-291.

30. Kumar N, Kumar R (2013) Nanotechnology and nanomaterials in the treatment of life-threatening diseases. William Andrew.

For possible submissions Click below: 